\title{
Integrating Statistics Labs Into Economics Electives
}

\author{
Ann L. Owen* \\ Hamilton College \\ January 2006
}

*198 College Hill Road, Clinton, New York 13323, phone: 315-859-4419, fax: 315-859-4477, e-mail: aowen@hamilton.edu. Elizabeth Jensen and Jeffrey Pliskin provided helpful comments. 


\title{
Integrating Statistics Labs Into Economics Electives
}

\begin{abstract}
Typically, undergraduate economics electives focus on content rather than methods, in spite of the fact that empirical work is fundamental to the practice of economics. This article describes an alternative approach to teaching content by using statistics labs that emphasize the empirical testing or applications of the theory. The result of this approach is that students develop an understanding of content in a way that more closely resembles the understanding of a research economist.
\end{abstract}


In spite of persuasive arguments in favor of moving away from lecture/exam formats for undergraduate economics classes, the vast majority of economics classes are still taught in the “chalk and talk" format. ${ }^{1}$ Some classes, most commonly statistics or econometrics, have an addon laboratory component in which students do engage in active learning of statistical techniques, while a few economics programs contain separate, stand-alone laboratory courses. In contrast, electives in an economics curriculum typically focus on content, rather than empirical methods.

The important feature of all these approaches is that the manner in which content is usually taught in an economics elective is divorced from what students learn in their methods classes. Ironically, many economists would argue that this dichotomy between content and methods betrays the nature of economics, and Colander (2005) presents evidence that graduate education in economics is increasingly emphasizing empirical skills. This article describes an alternative approach to using statistics labs that integrates content and methods. The result of this approach is that students develop an understanding of content in a way that more closely resembles the understanding of a research economist.

The second section of this paper describes the features of a good lab assignment for an elective class, the third section discusses the benefits and drawbacks of this approach, the fourth section discusses some details of this method applied to a course in economic growth, and the fifth section offers a concluding thought. Example assignments are included in the appendix.

\section{Features of a good lab assignment intended to teach theory}

The lab assignments in such a course consist of a small number of open-ended questions which students are required to answer using regression analysis. The nature of economics implies that much of what is taught in economics classes has empirical implications and the key

\footnotetext{
${ }^{1}$ See Becker and Watts (2001) for a survey of teaching methods in undergraduate economics courses.
} 
to creating a good assignment is to have students consider the evidence for these implications. The growing availability of free or inexpensive economic data on the Internet makes empirical work possible in almost any economics elective.

In designing the assignments, a key principle to keep in mind is that the purpose of the assignments is not to teach econometric methods, but to teach the students the content of the elective course. Therefore, the assignments should emphasize the implications of theory discussed in class, rather than the application of a "technique of the week" as can happen too often when the focus is on learning statistics. Depending on the ability levels of the students, the assignments might ask the students to replicate, with explanation, a result in their textbook or in a course reading. This same assignment can be made slightly more difficult by asking the question in a different way than students have seen in course material before. For more sophisticated students, the question could require them to extend material beyond that which was discussed in class. Assignments can also be made more challenging by giving less direction on the data and variables that should be used. In particular, assignments for which students are supposed to use all the data in a data set supplied by the instructor without transformations should be avoided because these kinds of assignments can be completed by students without an understanding of the material.

For example, in a macroeconomics, money and banking, or monetary policy class, students might be given a reading on inflation/output tradeoffs in which a Phillips curve is estimated with U.S. data. A relatively straightforward assignment would ask the students to reproduce this work either with data from the U.S. during a different time period or with data from a different country and to compare the results to those obtained in the reading, explaining 
any differences. A slightly more difficult assignment might ask students to arrive at an estimate of the cost of a one percentage point decrease in the inflation rate. Of course, to answer this question, the students need to estimate a Phillips curve, but they first need to realize that they do. Finally, an even more challenging assignment might ask students a similar question, but would not provide a reading and would require the students to either reason through an empirical specification or find a relevant article themselves. For students who are inexperienced in using empirical evidence for their ideas, these kinds of assignments are very challenging because the way economics is currently taught does not often require students to consider how to form empirical specifications consistent with their theories. Much of the value in teaching content via labs comes from this very exercise-developing and justifying an empirical specification requires students to think very precisely about their ideas.

A good source for timely and interesting lab questions for a variety of classes can be found in publications intended for a policy-oriented audience (e.g., Fed publications, World Bank publications, many papers written at public policy think tanks). Many of these kinds of articles present empirical analysis that is very accessible to students who have had one statistics class. Two example assignments are in the appendix.

The value of asking open-ended questions becomes apparent when the students turn in their lab assignments. Invariably, no two lab reports will be identical. This provides a great opportunity for in-class discussion in which students compare the results of their analysis. In the course of the discussion, the instructor can help students identify the sources of their differences — usually either different theoretical assumptions or different ways of empirically modeling the same assumption. This kind of discussion is a critical step in using this tool as a 
way of imparting a deeper understanding of the material, and an unavoidable byproduct of this discussion is a better understanding of the methods too. In small classes, this discussion can happen among the entire class. In larger classes, students can be divided into smaller groups and asked to report the conclusions of their comparisons to the larger group.

Opportunities to use this assignment to teach other important skills also exist. For example, writing skills can be improved if lab reports take on the same format as a mini-research paper, starting with an introduction and literature review that would discuss relevant readings and topics from the class. (A sample set of instructions for lab write-ups that require this level of writing is included in the appendix.) Oral presentation skills might also be taught with this assignment if students take turns presenting their results to the class.

In an economics elective, three to six of these assignments are generally enough to improve students' understanding of content through empirical methods. The sophistication of the labs should increase over the course of the semester, with a first lab perhaps just generating some descriptive statistics and motivating further work. Depending on the ability levels of the students, the labs can evolve to requiring more subtle ideas and more sophisticated specifications as the semester progresses (e.g., dummy variables, interaction terms, qualitative dependent variables, IV estimation, panel data models). Some of the lab assignments might require students to learn statistical techniques beyond basic multiple regression, however, the teaching of new statistical techniques in this context should be limited. Ideally, the course would be taught within a program that allowed students to be exposed to empirical analysis in a variety of electives to make the economics curriculum more cohesive. In such a case, if each course 
focused on only a few additional techniques, it would be feasible to expose students to a variety of advanced techniques over the course of their undergraduate career.

\section{Benefits and Drawbacks}

There are many benefits to this approach to teaching undergraduate economics. One of the most important is that students will actually use the techniques they learn in their statistics classes, allowing students to make connections across classes. Even if students are currently using their knowledge of statistics to read material in more advanced courses, as we all know, there is a big difference between reading about statistical analysis and doing it yourself.

Another important benefit is that lab assignments offer students an alternative way of demonstrating their knowledge other than in-class exams. Diversifying the types of assignments helps the course appeal to students with different learning styles. In addition, the empirical understanding of important concepts gained through these types of assignments is a different kind of understanding than that gained by reading a textbook. Students who are working on lab assignments, even at a rudimentary level, will have a better understanding of assigned readings, including those that use more sophisticated empirical techniques. Thus, this approach complements well the standard way of learning economics.

Lab assignments also lend themselves well to giving assignments at different levels of difficulty. By requiring more sophisticated techniques or ideas, it is relatively easy to increase the difficulty of the assignments as the semester progresses, ensuring that students are challenged throughout the course. Furthermore, the process of considering appropriate empirical evidence for ideas can be quite difficult for students as they typically do not get many opportunities to do 
this as undergraduates. For those instructors who want to design classes that appeal particularly to hard-working and intellectually curious students, this approach is very useful.

Often, these kinds of assignments can help students get started on their own research project. Work initially done as part of an in-class lab assignment, especially one that relies on an open-ended question, can expand and evolve into a student's senior thesis or an independent research project. Realistically, lab assignments in a course will not turn into publishable research, but the exposure to the process can be a valuable and important first step in learning how to do empirical research. For the few students who are contemplating graduate school, lab assignments of this type can give them exposure to the research process that will be helpful to them as they enter an economics Ph.D. program.

Another benefit of this approach is that it accommodates extensions that facilitate the teaching of other important skills such as writing and speaking. As mentioned earlier, by requiring students to write-up their results in a paper or present their results to the class in an oral presentation, students can also be taught writing and speaking skills.

Finally, teaching in this way has personal benefits for the instructor. It often leverages our own expertise as economists; and, for those in environments in which teaching and research is carefully balanced, it encourages a synthesis of the two activities.

Of course, there are drawbacks. The two most important are related to additional constraints imposed by this method of teaching. First, in order to keep the course focused on content and not statistical technique, it is important for students to take a statistics course that teaches multiple regression analysis prior to taking the elective. This has the disadvantage of potentially discouraging students from studying economics as it puts another hurdle in front of 
students interested in the material taught in the elective classes. Also important, however, is the fact that this teaching method potentially requires more resources (i.e., smaller student to faculty ratios). Students answering open-ended questions may require more help from instructors. In addition, to the extent that writing or speaking assignments are given in conjunction with the lab assignments, class sizes may need to be reduced to make these components successful as well. However, these tradeoffs may be worthwhile if one of the goals of an undergraduate economics program is to give students exposure to economic research principles and practice.

\section{Details on the assignment: An example from an economic growth class}

Although this teaching technique has a wide application in most fields taught in the undergraduate economics curriculum, this section provides more detail on how this strategy has been implemented in my class in economic growth. This class is an upper-level elective with prerequisites of intermediate micro, intermediate macro, and an economic statistics class in which students have been introduced to the concept of multiple regression. In addition to the labs, students in this class are also responsible for reading carefully selected journal articles with empirical components that complement the lab assignments in class. Each of them takes a turn making a 10 to 15 minute presentation of the main points of one article and relating them to previous articles and class discussions. Several of the students in the class are completing a capstone experience for the major and are required to write a final paper that makes a policy recommendation that enhances long-run growth in a specific country and uses regression analysis as supporting evidence for at least one of their points. The labs in the class prepare the 
students for being able to complete this final assignment, which is one step closer to independent research. An example of the senior project assignment is included in the appendix. ${ }^{2}$

The level of econometric sophistication of the students is relatively low at the beginning of the semester. Students generally know how to run multiple regressions, but have not had much practice doing it and don't have clear ideas of how to match up theory and evidence. I do spend one class at the beginning of the semester reviewing key regression concepts, but most of the learning of statistics methods in this class is accomplished as the students themselves develop a need to know more about methods because they come to understand that they need to use them.

The first lab of the semester is completed within the first two weeks of classes and its purpose is to simply introduce students to the data and some facts about the world distribution of income that motivate many of the topics of the course throughout the semester. I do compile one large data set for use for all the labs and make that available to the students. The data set contains about 100 variables compiled from World Bank Development Indicators, Penn World Tables, and data made available by authors of journal articles. Although it is true that much of the data for many macroeconomic topics can be found on the Internet, manipulation of that data can be time consuming for the students and it is a much more effective learning experience if the students spend more of their time on analysis. After the first, mostly descriptive lab, subsequent labs in the class require students to become more sophisticated in their analysis. The next lab requires students to use multiple regression analysis to explain an important growth variable such as investment or education and a third lab might require even more sophistication by requiring students to transform variables or use interaction terms to support their ideas. As might be

\footnotetext{
${ }^{2}$ The students who are enrolled in the class but not completing the senior project do an alternative, less rigorous assignment.
} 
expected in a course in economic growth, endogeneity and causality are key issues in the journal articles the students are reading, and we do spend some class time discussing the importance of and ways of addressing these issues. The last lab of the semester requires them to address these issues, possibly with instrumental variables estimation.

Each lab is started in class, although students cannot finish them in one class period. I do require that, in the initial lab period, they work with one other person in the class to help them get started, but give them the option to do a joint or independent write-up. In teaching during the actual lab period, it is important to balance the students need for clear direction against the benefit of allowing them to think about questions for which there is not obviously a right answer. I do emphasize to the students that they need to start with their ideas and then work out the empirical implication of these ideas. Although giving them one large data set with many variables reduces the temptation to run hundreds of regressions, the concept that the theory should determine the empirics can be difficult for some students.

Much of the teaching during this initial lab period is, in fact, comprised of conversations with the students about exactly what their ideas are. As students make progress during the lab period, they can be prodded into fruitful directions with leading questions from the instructor. Examples of these kinds of questions include: "Do you think each year of education is equally valuable?", "Will the effect be the same in poor countries and rich countries?", or "Do you think investment in 2000 can affect growth over the 1960 to 2000 time period?" These questions are then followed up with more specific questions about what their answer implies about the empirical specification (e.g., dummy variables, interaction terms, appropriate time lags.) My 
goal at the end of each lab period is to have every student leave with an understanding of the question they are answering in the lab and the methods they will use to answer it.

Although some students admit that they do not like what is perceived to be extra work in this class, almost all of them recognize the value. Comments from student course evaluations from this course indicate that many students find this experience to be rewarding and challenging. For example, one student wrote, "I really liked the way the course was designed...we were able to take what we learned and apply it instead of studying just a bunch of graphs." Another student in the same class echoed that sentiment, "The class wasn't simply based on the textbook—we found our own evidence to support the theories."

\section{Conclusion}

Integrating lab assignments into economics electives can improve students' understanding of core course material and give the students opportunities to study economics by doing work that is similar to that done by many economists. They also provide opportunities to teach a broad skill set that is important to many undergraduate economics majors. The key feature of these assignments is that their primary purpose is to use empirical methods to teach economic theory. 


\section{Appendix A: Sample lab for a money and banking, monetary policy, or macroeconomics elective}

\section{Determinants of Inflation Expectations}

Expectations play a very important role in determining future economic activity; and, in this lab, you will explore the determinants of inflation expectations.

The data provided in the file, lab3.dta, includes a measure of inflation expectations from the Philadelphia Fed Survey of Professional Forecasters. The data in the variable called, expinfl, is the one year-ahead forecast of annual inflation by the respondents to this survey. In other words, the data for the $4^{\text {th }}$ quarter of 2005 represents the forecast of annual CPI inflation made for $2005: Q 4$ in the $4^{\text {th }}$ quarter of 2004.

As you consider the appropriate empirical specification, please be sure to consider the appropriate lags of variables to use in your regression as well as whether the relationships you are testing require you to consider levels or growth rates of your independent variables.

A thorough write-up will

- Describe the economic theory behind the development of your regression equation

- Discuss the importance of expectations in determining economic activity and the importance of these expectations for monetary policy makers

- Discuss different theories of expectation formation and the support that your results provide for each.

- Evaluate your regression equation and discuss the relative importance of each of the independent variables you use in your regression in influencing expectations.

With the exception of the inflation expectations data which was obtained from the Philadelphia Fed, all data for this lab was obtained from Economagic.com. Variable labels in the Stata data set provide data definitions. 


\section{Appendix B: Sample lab for a development, economic growth, or labor course.}

\section{The Value of Education}

Policy makers often have to make difficult choices about the best way to allocate limited resources. Education is one means of making workers more productive and raising incomes. But, of course, resources spent on education are resources not spent in some other potentially useful way.

In this lab you will help to inform this policy decision by answering the question: What is an extra year of education worth? More specifically: If the average education of the labor force is increased by one year, how much higher can the typical country expect per capita income to be 25 years from now?

In determining how to answer this question, be sure to draw on the growth theory that you have already learned. Discuss your regression specification, the confidence that you have in your results and consider potential omitted variables as well as the direction of causation between your dependent and independent variables.

Keep in mind that your overall objective is to provide information that would be helpful to policy makers. Therefore, be sure to explain your data and methods and include a recommendation in your conclusion.

Note: This lab is one of several labs written by the author to accompany Weil (2005). More examples of several labs designed for a course in Economic Growth by the author can be viewed at http://wps.aw.com/aw_weil_econgrowth_1/0,9337,1443702-,00.html. ${ }^{3}$

\footnotetext{
3 "Exhibit B," found on the website http://wps.aw.com/aw_weil econgrowth $1 / 0,9337,1443702-, 00 . h t m l$, the online accompanyment to the text Weil, Economic Growth, copyright 2005 Pearson Education, Inc. Reprinted by permission of Pearson Education, Inc., publishing as Pearson Addison Wesley. All rights reserved.
} 


\section{Appendix C: Sample write-up instructions for a course that emphasizes writing.}

All lab reports should contain the following sections.

Executive Summary/Abstract

In this section you will succinctly state your main findings. Often this section will be only a few sentences, but a reader of this section should be able to determine quickly what you have done and what your conclusions are. This section should be written after the rest of the paper is completed.

Introduction and Literature Review

In this section, you will introduce the question you are trying to answer or the hypothesis you are testing. You should motivate the reader in this section by explaining the importance of this question. You should also review the current literature related to your question (i.e., the class readings and the textbook) to help to put your work in context.

Data Description

In this section you will describe the source and nature of your data. Often descriptive statistics (e.g., means and standard deviations) are presented as a way of introducing your data.

\section{Analysis}

The analysis section contains the details of your investigation. In this section you should explain your method of analysis. In other words, you should answer the question: Why did you use the techniques you used to answer the question you posed in the introduction? You should also present your results in this section. Often, you will include graphs or tables that summarize your results.

\section{Conclusion}

In the final section of your lab, you should state your main conclusions. You should discuss any important limitations of your analysis, stating what data or information you would have liked to have in order to answer your questions more thoroughly. 


\section{Appendix D: Sample Assignment for a Capstone Experience}

There are two required parts of this assignment: a research paper and an oral presentation during the last week of classes.

\section{$\underline{\text { Assignment }}$}

You have been hired as a consultant to the government of a specific country to analyze that country's current prospects for growth and make recommendations for policies that could help to improve that country's growth performance. Your assignment for this class is to prepare a written report and give an oral presentation stating your findings. In writing your report, you can assume that the government officials have taken (and passed!) all the prerequisites for this class.

Each of your recommendations must be justified with either economic theory or with some empirical evidence that you supply (i.e., you need to run a regression.) At least one of your recommendations must be supported by theory and at least one must be supported by theory and empirical evidence. (You may have as many as 4 or 5 recommendations in total). You should also use the results of economics journal articles to support your points.

\section{Choosing a Country}

You must choose a country by Nobody may choose to study the United States. To ensure that everybody learns something from your presentation, each senior project student must choose a different country, preferably in different regions of the world (e.g., Latin America, East Asia, SubSaharan Africa, Europe, Former Soviet Bloc countries, North America). Countries will be assigned on a first-come/first-serve basis. Prior to selecting your country, I highly recommend that you do some preliminary reading to make sure that the issues facing your country are of interest to you.

Two sources of country-specific information are the International Monetary Fund and the World Bank (see links on this course's home page). The staff of the International Monetary Fund periodically prepares Country Reports that give detailed information on many countries. (Go to the IMF web site, click on publications and then search on IMF Staff Country Reports to see a list of the reports available. Many can be downloaded from the Internet immediately, but some are only available in hard copy, and obtaining them involves both a fee and a delay.)

\section{$\underline{\text { Guidelines }}$}

Your paper should be approximately 15 pages in length (excluding exhibits), however, the length of your paper may vary slightly from this number, depending on the issues you discuss. However, if you find that your paper is less than 14 pages, you should reconsider whether or not you have covered the topic thoroughly. Under no circumstances should you write a paper that is longer than 20 pages.

The oral presentation should last between 15 and 20 minutes. Presentations that are longer than 20 minutes will be stopped before they are completed. 


\section{References}

Becker, William E. and Michael Watts, 2001, "Teaching Methods in U.S. Undergraduate Economics Courses," Journal of Economic Education, 32(3): 269-279.

Collander, David, 2005, "The Making of an Economist Redux," Journal of Economic Perspectives, 19(1): 175-198.

Weil, David N., 2005, Economic Growth (New York: Pearson Addison Wesley). 